Research Article

\title{
Assessment of Uncertainties in Energetic and Exergetic Performances of a Flat Plate Solar Water Heater
}

\author{
Intissar Harrabi $\mathbb{D}^{1},{ }^{1}$ Mohamed Hamdi $\mathbb{D}^{2},{ }^{2}$ and Majdi Hazami ${ }^{1}$ \\ ${ }^{1}$ Thermal Process Laboratory, Research and Technology Centre of Energy, BP 95, Hammam-Lif 2050, Tunisia \\ ${ }^{2}$ Laboratory of Wind Power Control and Waste Energy Recovery, Research and Technology Centre of Energy, BP 95, \\ Hammam-Lif 2050, Tunisia
}

Correspondence should be addressed to Intissar Harrabi; harrabiintissar55@gmail.com

Received 19 October 2020; Accepted 19 November 2020; Published 9 December 2020

Academic Editor: Haoran Zhang

Copyright (c) 2020 Intissar Harrabi et al. This is an open access article distributed under the Creative Commons Attribution License, which permits unrestricted use, distribution, and reproduction in any medium, provided the original work is properly cited.

\begin{abstract}
This paper aims to quantify sensitivities of energy and exergy performances of Flat Plate Solar Water Heaters (FPSWHs) with respect to measurement parameters. For that purpose, a computational tool is developed and validated by using outdoor conditions according to the test standard EN 12975. First of all, numerical simulations are compared with experimental results and available data in the literature, and the comparison shows a good agreement. Then, we apply the proposed model to the quantification of uncertainties associated with transient simulation. Results show that ambient temperature is the main relevant factor in operating conditions, and its effect reaches $13.7 \%$ and $3.89 \%$ on energy and exergy efficiencies, respectively, when the deviation in the sensor measurement is about $\pm 1^{\circ} \mathrm{C}$. When $0.15 \mathrm{v} \%$ multiwall carbon nanotubes (MWCNT)-Ethylene-Glycol (EG) $(30: 70)$ nanofluid is used as working fluid, results show that a suitable choice of nanofluid properties achieves $84.7 \%$ of the thermal efficiency during the zero reduced temperature conditions compared to $75.4 \%$ when the collector works with E-G. Using common empirical correlations affects substantially the accuracy of the fitting parameters, and the deviation in exergy efficiency reaches $1.18 \%$.
\end{abstract}

\section{Introduction}

There is evidence that the investment in solar water heater installations is reversed by gaining electricity for the first 4 to 5 years, and then the hot water becomes free during the life time of equipment over 15 years. In addition, governments provide subsidized loans to finance equipment costs. For our country, Tunisia, the solar water heater market has grown significantly in recent years thanks to the subsidy granted by the program to promote the use of the solar water heater ( $35 \%$ of the purchase price is refunded), which is among the projects eligible for the Clean Development Mechanism (CDM). This mechanism represents one of the three flexibility mechanisms provided in Article 12 of the Kyoto Protocol of Climate Change Convention signed by Tunisia [1]. To reach this goal, prior to the sale of a Solar Water Heater (CES), each supplier must submit to the National
Agency of Energy Management (ANME) a specific eligibility file for each proposed model. Several studies have been carried out in the direction of perfecting solar water heaters, and currently, there are several international standards that set the test methods for solar water heaters in order to predict their performance. Among the global testing methods, we mention the DST test procedure that was developed in Germany, and that has been registered as ISO 9459-5. Moreover, it is for this reason that about hundreds of technical papers and reports of Performance Test according to the DST procedure have been elaborated on request in Research and Technology Centre of Energy (CRTEn). The second test procedure (Input/output) does not require a study of the whole system, i.e., without the storage tank.

In fact, all test procedures aim to evaluate the thermal efficiency of solar collectors; a few investigations [2] are found in the literatures that are interested in studying their 
exergy efficiencies. Kalogirou et al. [3] reviewed the exergy analysis of solar thermal collectors. They gave a clear methodology of exergy analysis of solar collectors. They highlighted that exergy is more representative of performance evaluation. Farahat et al. [4] carried out a numerical study to optimize the exergy performance of flat plate solar collectors by using design parameters. They validated their code experimentally under given design and operating conditions. Their results showed that there exist optimum values of the maximum exergy efficiency for a specific mass flow rate and absorber area.

In general, numerical tools are used in order to validate the experimental results. The latter often shows several uncertainties that directly affect the collector's performances. The physics community usually defined an interval of "probable" values of the quantity to be measured in which we have a $95 \%$ chance of finding the "true value." We are talking about $95 \%$ confidence interval. Several authors have been interested in uncertainty tests for solar water heaters. Tang et al. [5] used a test standard published by the National Technology Supervision Bureau of China in 1997 to assess the uncertainty of heat loss coefficient, $U_{\mathrm{L}}$, of a glass evacuated solar collector tube. They found that the choice of the test procedure is the most influencing parameter on the evaluation of $U_{\mathrm{L}}$. Their results also showed that measuring errors of instruments contributed little to $U_{\mathrm{L}}$. Kicsiny [6] validated a model based on Multiple Linear Regression (MLR) for solar collectors. They showed that the MLR-based model has a lot of precision than models working on regression in the literature. Their results showed that the proposal based on the MLR model is considered to be the simplest black box with a precision greater than $5 \%$. They also showed that the MLR-based model gives collector output temperature results with higher accuracy than the physically based model. Facão and Oliveira [7] presented a new method in order to evaluate heat pipe solar collector efficiency. They analyzed the uncertainty by separating systematic and random uncertainties. Their results showed that the uncertainty of efficiency is higher for smaller values of $\left(T_{\text {fm }}-T_{\mathrm{a}}\right) / G$, where $T_{\mathrm{fm}}, T_{\mathrm{a}}$, and $G$ are the fluid mean temperature, the ambient temperature, and the solar incident irradiation, respectively. Sowmy et al. [8] evaluated the uncertainty in the efficiency tests of conventional flat plate solar collectors by using a solar simulator. They performed indoor tests for the uncertainty estimation associated with the determination of efficiency. They evaluated the contribution of the errors in the instrumentation, the test conditions, and the statistical regression. Their results showed that using an artificial solar simulator is primordial in order to obtain good accuracy. Their study also showed that regression uncertainties also have a significant effect as measurement uncertainty on the results. Mathioulakis et al. [9] performed a systematic analysis of the contribution of all components of uncertainty based on the ISO 9806-1 procedure test to determine the final uncertainty in the parameters of the characteristic equation and the instantaneous efficiency of the collector. They proposed a step-by-step methodology that uses specific statistical tools to assess the reliability of the test procedure and also to quantify the quality of the adjustment. Their results showed that the stepwise methodology is a reliable and efficient tool to predict the performance of the collector by considering the efficiency of the collector a key parameter. Unlike the ISO 9806-1 standard which does not provide the uncertainty of the parameters of the efficiency curve, Sabatelli et al. [10] conducted an experimental study in order to find the uncertainty of curve fitting parameters. In their study, the authors proposed a methodology to solve this problem and to evaluate not only the parameters and their uncertainties, but also the reliability of the test procedure and its effectiveness aptitude. They performed a sensitivity analysis to evaluate the effects of measurement errors on the uncertainty values in the estimates settings.

Regression Models and Sensitivity Analysis for the Thermal Performance of solar collectors were also studied by Rehman et al. [11]. The authors used the water, 20\% glycol-water, and $40 \%$ glycol-water as working fluids. They found that the coefficients of determination exceed $97 \%$ for the efficiency models and $93 \%$ for the fluid outlet temperature. They also performed a sensitivity analysis to determine the most influential design, operational and natural parameters on the collector's efficiency. Karwa and Baghel [12] used a mathematical model to study the effect of measurement uncertainties on the thermohydraulic performance of solar plate heaters. They showed that, based on thermohydraulic consideration, the driving height is $10 \mathrm{~mm}$ is preferable. Their results also showed that uncertainty in the wind heat transfer coefficient could affect the thermal efficiency by $2.6 \%$. The efficiency varies by $1.3 \%$ when the sky temperature varies by $5 \mathrm{~K}$. This efficiency was affected by approximately -1.5 to $1.3 \%$ by varying the solar irradiation from 500 to $1000 \mathrm{Wm}^{-2}$. Their study also showed that by increasing the flow, these effects decrease. They are lower for the collector with a selective coating on the surface of the absorbing plate.

As described above, the determination of the influence input parameters on the efficiency of solar collectors attracted the intention of several studies in recent years. The determination of tolerances and the effect of uncertainties measurement on the results is essential for designing solar collectors and influences the manufacturing costs. This also helps in evaluating and comparing possible configurations of these systems. The studies carried out in this area are limited and require further investigation essentially in terms of exergy performances. The aim of this study is to quantify some pertinent parameter sensitivities on both energy and exergy performances of a FPSWH. We focus on better understanding the origin of different sources of deviation in energy and exergy efficiencies estimation during solar collector test motivated by applications that aim to improve solar water heaters. In the following section, we describe the solar collector tested in the Research and Technology Centre of Energy (CRTEn), the mathematical model, and the solution procedure taken to analyze the effect of uncertainties of mentioned parameters on thermal behavior and exergy performance of the system. 


\section{Mathematical Model}

As described previously, the aim of this work is to quantify the effects of several operating parameters on the energy and exergy efficiencies of a FPSC. For this reason, it is essential to develop an efficient numerical tool allowing quantifying the uncertainties in the FPC's performances. For this purpose, a validation step is necessary. The validation of the code helps to determine if the mathematical model is able to investigate the heat transfer and control the exchange of entropy in the system. The test of the solar collector is carried out according to EN 12975 procedure. Solar collector testing determines the reliability and efficiency characteristics of a collector. Knowledge about efficiency makes it possible to optimize the cost/benefit ratio and to classify the performance of collectors in the productive sector. As a result of the test, it is possible to compute the energy that the collector will produce in a specific climate region.

The model used in this study is the one-dimensional mathematical model previously used by Zima and Dziewa [13], Saleh [14], Saleh et al. [15], and Cadafalch [16]. This model consists of five nodes and thus a system of five equations. It has been shown that this model is useful for analyzing the influence of the mass flow rate on the performance of the collector and also the analysis of the determination of the real time collector's performances. This model can be applied to the collectors in a serpentine or parallel tube arrangement configuration with single or double covers [13]. The energy balance equation for the glass cover is written as follows:

$$
\begin{array}{r}
C_{\mathrm{g}} \rho_{\mathrm{g}} V_{\mathrm{g}} \frac{\mathrm{d} T_{\mathrm{g}}}{\mathrm{d} t}=\left[\left(h_{r_{\mathrm{g}-\mathrm{am}}}+h_{c_{\mathrm{g}-\mathrm{am}}}\right)\right. \\
\left(T_{\mathrm{am}}-T_{\mathrm{g}}\right)+h_{r_{\mathrm{ab}-\mathrm{g}}}\left(T_{\mathrm{ab}}-T_{\mathrm{g}}\right) \\
\left.+h_{c_{\mathrm{g}-\mathrm{a}}}\left(T_{\mathrm{a}}-T_{\mathrm{g}}\right)+\alpha G\right] p \Delta \mathrm{z},
\end{array}
$$

where $C_{g}$ is the specific heat of the glass cover, $\rho_{g}$ and $V_{q}$ are its density and volume, respectively. $T_{\mathrm{am}}, T_{\mathrm{g}}, T_{\mathrm{ab}}$ and $T_{\mathrm{a}}$ are the ambient, the glass, the absorber, and the air gap temperature, respectively. $\alpha$ is the absorption coefficient. The radiation heat transfer coefficient between the outer surface of the glass cover and the ambient is computed as follows:

$$
h_{r_{\mathrm{ab}-\mathrm{g}}}=\frac{\sigma\left(T_{\mathrm{ab}}^{2}+T_{\mathrm{g}}^{2}\right)\left(T_{\mathrm{ab}}+T_{\mathrm{g}}\right)}{\left(1-\varepsilon_{\mathrm{ab}} / \varepsilon_{\mathrm{ab}}\right)+\left(1 / F_{\mathrm{ab}-\mathrm{g}}\right)+\left(\left(1-\varepsilon_{\mathrm{g}}\right) / \varepsilon_{\mathrm{g}}\right)\left(A_{\mathrm{ab}} / A_{\mathrm{g}}\right)},
$$

where $F_{\mathrm{ab}-\mathrm{g}}$ is the view factor between two surfaces of absorber and glass. The radiation transfer coefficient between the glass and the ambient is computed as the following:

$$
h_{r_{\mathrm{g}-\mathrm{am}}}=\frac{\sigma \varepsilon_{\mathrm{g}}\left(T_{\mathrm{g}}^{4}-T_{\mathrm{sky}}^{4}\right)}{T_{\mathrm{g}}-T_{\mathrm{am}}} .
$$

$h_{c_{\mathrm{c}-\mathrm{a}}}=\mathrm{Nu}_{\mathrm{a}} \lambda_{\mathrm{a}} / \delta_{\mathrm{a}}$ is the convective heat transfer coefficient between the absorber and the air gap, where $\mathrm{Nu}_{\mathrm{a}}$ is the average Nusselt number for the air gap computed as follows [17]:

$$
\mathrm{Nu}_{\mathrm{a}}=\max \left\{0,\left(1+1.44\left[1-\frac{1708[\sin (1.8 \gamma)]^{1.6}}{\mathrm{Ra} \cos (\gamma)}\right]\left(1-\frac{1708}{\mathrm{Ra} \cos (\gamma)}\right)+\left[\left(\frac{\mathrm{Ra} \cos (\gamma)}{5830}\right)^{0.33}-1\right]\right)\right\},
$$

$\gamma$ is the collector inclination angle and $\mathrm{Ra}=g \beta \Delta \mathrm{TL}^{3} / \nu \alpha$ is the Rayleigh number. $\alpha, \lambda_{\mathrm{a}}, \delta_{\mathrm{a}}, A_{\mathrm{ab}}, \varepsilon_{\mathrm{g}}$ and $A_{\mathrm{g}}$ are the absorption coefficient, the thermal conductivity, the air gap thickness, the absorber area, and the emissivity of the cover glass and its area, respectively.

$h_{c_{\mathrm{g}-\mathrm{am}}}=\mathrm{Nu}_{\mathrm{am}} \lambda_{\mathrm{am}} / \delta$ is the convective heat transfer coefficient between the glass and the ambient. $\mathrm{Nu}_{\mathrm{am}}$ is the average Nusselt number for the ambient defined as follows [18]:

$$
\mathrm{Nu}_{\mathrm{am}}=0.86 \operatorname{Re}_{\mathrm{am}}^{0.5} \operatorname{Pr}_{\mathrm{am}}^{0.33}
$$

$\mathrm{Re}_{\mathrm{am}}$ is the ambient Reynolds number, $\mathrm{Pr}_{\mathrm{am}}$ is the Prandtl number of the ambient air. $G$ is the heat flux of solar radiation, $p$ is the tube pitch, $\Delta z$ is the spatial size of control volume, $\sigma$ is the Stefan-Boltzmann constant, $\varepsilon_{g}$ is the emissivity of the glass, and $T_{\text {sky }}=0.0552 T_{\text {am }}^{1.5}[19]$ is the sky temperature. The energy balance on an elemental volume of the air gap gives the following:

$$
C_{\mathrm{a}} \rho_{\mathrm{a}} V_{\mathrm{a}} \frac{\mathrm{d} T_{\mathrm{a}}}{\mathrm{d} t}=\left[h_{c_{\mathrm{g}-\mathrm{a}}}\left(T_{\mathrm{g}}-T_{\mathrm{a}}\right)+h_{c_{\mathrm{ab}-\mathrm{a}}}\left(T_{\mathrm{ab}}-T_{\mathrm{a}}\right)\right] p \cdot \Delta z
$$

where $C_{\mathrm{a}}, \rho_{\mathrm{a}}, V_{\mathrm{a}}, T_{\mathrm{a}}, T_{\mathrm{ab}}$ are, respectively, the specific heat of the air, its density, its volume, its temperature, and the absorber temperature.

The energy balance equation for the absorber is written as follows:

$$
\begin{aligned}
C_{\mathrm{ab}} \rho_{\mathrm{ab}} V_{\mathrm{ab}} \frac{\mathrm{d} T_{\mathrm{ab}}}{\mathrm{d} t}=[ & \tau \alpha G+h_{r_{\mathrm{ab}-\mathrm{g}}}\left(T_{\mathrm{g}}-T_{\mathrm{ab}}\right)+h_{c_{\mathrm{g}-\mathrm{a}}}\left(T_{\mathrm{a}}-T_{\mathrm{ab}}\right) \\
& \left.+\frac{\lambda_{\mathrm{is}}}{\delta_{\mathrm{is}}}\left(T_{\mathrm{is}}-T_{\mathrm{ab}}\right)\right] p \cdot \Delta z \\
& +\pi d_{\mathrm{in}} h_{\mathrm{f}} \Delta z\left(T_{\mathrm{f}}-T_{\mathrm{ab}}\right),
\end{aligned}
$$

where $h_{c_{\mathrm{ab}-\mathrm{a}}}=h_{c_{\mathrm{g}-\mathrm{a}}}$ and $h_{\mathrm{f}}=\mathrm{Nu}_{\mathrm{f}} \lambda_{\mathrm{f}} / d_{\text {in }}$ is a transfer on the internal surface of the collector tube. The empirical formula of Heaton et al. [20] using the assumption that the flow is fully developed and is used as follows: 


$$
\mathrm{Nu}_{\mathrm{f}}=4.4+\frac{0.00236\left(\operatorname{Re}_{\mathrm{f}} \operatorname{Pr}_{\mathrm{f}}\left(d_{\text {in }} / L\right)\right)^{1.66}}{1+0.00857\left(\operatorname{Re}_{\mathrm{f}} \operatorname{Pr}_{\mathrm{f}}\left(d_{\text {in }} / L\right)\right)^{1.13}} ; \quad 1<\operatorname{Re}_{\mathrm{f}} \operatorname{Pr}_{\mathrm{f}} \mathrm{d}_{\mathrm{in}} / L \leq 1000
$$

$\lambda_{\mathrm{f}}$ is the fluid thermal conductivity, $d_{\text {in }}$ is the inner diameter of the collector tube, $L$ is the length of the analyzed collector, $\lambda_{\text {is }}$ is the thermal conductivity of insulation, $\delta_{\text {is }}$ is its thickness, $\sigma$ is Stefan-Boltzmann constant, $\varepsilon_{\mathrm{ab}}$ is the emissivity on absorber, and $\varepsilon_{\mathrm{g}}$ is the glass emissivity.

The energy balance equation for the insulation:

$$
C_{\text {is }} \rho_{\text {is }} V_{\text {is }} \frac{\mathrm{d} T_{\text {is }}}{\mathrm{d} t}=\frac{\lambda_{\text {is }}}{\delta_{\text {is }}}\left(T_{\mathrm{ab}}-T_{\text {is }}\right)+\left(h_{r_{\text {is-am }}}+h_{c_{\text {is }-\mathrm{am}}}\right)\left(T_{\mathrm{am}}-T_{\mathrm{is}}\right),
$$

where $C_{\text {is }}$ is the specific heat of the insulation, $\rho_{\text {is }}$ is its density, $V_{\text {is }}$ is its volume, and $T_{\text {is }}$ is the insulation temperature.

The radiation transfer coefficient between the insulation and the ambient is computed as follows:

$$
h_{r_{\text {is-am }}}=\frac{\sigma \varepsilon_{\text {is }}\left(T_{\text {is }}^{4}-T_{\text {sky }}^{4}\right)}{T_{\text {is }}-T_{\text {am }}} .
$$

The energy balance equation for working fluid (water):

$$
C_{\mathrm{f}} \rho_{\mathrm{f}} p \cdot \Delta z \frac{\mathrm{d} T_{\mathrm{f}}}{\mathrm{d} t}=\pi d_{\mathrm{in}} h_{\mathrm{f}}\left(T_{\mathrm{ab}}-T_{\mathrm{f}}\right)-\dot{m}_{\mathrm{f}} c_{\mathrm{f}} \frac{\partial T_{\mathrm{f}}}{\partial z},
$$

where $p, \Delta z, d_{\text {in }}$ and $h_{\mathrm{f}}=\mathrm{Nu}_{\mathrm{f}} \lambda_{\mathrm{f}} / d_{\text {in }}$ are the tube pitch, the spatial size of the control volume, the inner diameter of the collector tube, and the heat transfer on the internal surface of the collector tube, respectively. Based on the above equations, we can calculate the thermal efficiency of the collector as follows:

$$
\eta_{\mathrm{en}}=\frac{\dot{\mathrm{Q}}_{\mathrm{u}}}{G}=\frac{\dot{m} C_{\mathrm{p}}\left(T_{\mathrm{out}}-T_{\mathrm{in}}\right)}{G},
$$

where $\dot{Q}_{u}$ is the useful heat rate to the fluid. The exergy efficiency of the solar collector measures the deviation of the real process from the ideal one. It is given as follows [3]:

$$
\eta_{\mathrm{ex}}=\frac{\dot{E} x_{\mathrm{out}, \mathrm{f}}-\dot{E} x_{\mathrm{in}, \mathrm{f}}}{\dot{E} x_{\mathrm{s}}}=\frac{g\left(T_{\mathrm{out}}, T_{\mathrm{in}}, T_{\mathrm{am}}\right)}{f\left(T_{\mathrm{s}}, T_{\mathrm{am}}\right)}\left(\frac{\dot{\mathrm{Q}}_{\mathrm{u}}}{\dot{\mathrm{Q}}_{\mathrm{s}}}\right),
$$

where $g$ and $f$ are computed using the Farahat's proposal [4], which assumes zero pressure drop in the collector. In equation (13), the solar exergy is obtained using the Jeter expression [21] and $T_{\mathrm{s}}=5770 \mathrm{~K}$ is the apparent black body temperature of the sun, where $T_{\text {out }}$ is the output temperature, $T_{\text {in }}$ is the input temperature, and $T_{\text {am }}$ is the ambient one and where the two functions $f=\dot{E} x_{\mathrm{s}} / \dot{Q}_{\mathrm{s}}$ and $g=\left(\dot{E} x_{\text {out }, \mathrm{f}}-\dot{E} x_{\text {in, } \mathrm{f}}\right) / \dot{Q}_{\mathrm{u}}$ express the ratio of the solar radiation exergy rate to the solar radiation heat rate on the collector and the ratio of the exergy increase of the fluid to the useful fluid heat rate, respectively. $\dot{E} x_{\mathrm{s}}$ is the solar radiation exergy and $\dot{Q}_{s}$ is the solar radiation heat rate on the collector.

In order to evaluate the effects of the uncertainty of the experimental measurement equipment on the precision of the energy and exergy efficiencies, the theoretical uncertainty of the functioning parameters, $F$, was evaluated assuming that it depends on the operating parameters $\left\{x_{1}, x_{2}, \ldots, x_{n}\right\}$ and according to the following relationship:

$$
u_{\mathrm{F}}^{2}=\left(\frac{\partial F}{\partial x_{1}} u_{x_{1}}\right)^{2}+\left(\frac{\partial F}{\partial x_{2}} u_{x_{2}}\right)^{2}+\cdots+\left(\frac{\partial F}{\partial x_{n}} u_{x_{n}}\right)^{2}
$$

where $u_{x_{1}}, u_{x_{2}}, u_{x_{n}}$ are the independent uncertainties of parameters $\left\{x_{1}, x_{2}, \ldots, x_{n}\right\}$. The derivative of $F$ is computed by using first-order finite difference approximation as follows:

$$
\frac{\partial F}{\partial x_{i}}=\frac{F\left(x_{i}+\Delta\right)-F\left(x_{i}-\Delta\right)}{2 \Delta}+\mathcal{O}(\Delta)
$$

where $\Delta$ is the standard deviation of the value of the operating parameter $x_{i}$.

\section{Model Validation}

3.1. Validation with Existing Literature Data. Numerical simulation enables a better understanding of the physical phenomena involved in heating the solar collectors' working fluid and also assists in the proper sizing of thermal systems. It also provides an advantage over experimental testing as it is a lower cost tool as there is no need for sophisticated instruments and prototypes. Saleh [15] developed a mathematical model for simulating the transient behavior of a flat plate solar collector. The mathematical model was solved numerically by using an implicit scheme. He validated his model experimentally and found that the calculation scheme is useful for transient simulations of energy systems. Hilmer et al. [22] developed a model of first-order partial differential equations in order to calculate the short-term dynamic behavior of solar collectors for various mass flow rates. This model is applied for a large unglazed collector for heating a public outdoor pool in Marburg (Germany). Their results showed that the simple single-capacity model gives a high accuracy even for very wide flow rates by using average hourly values of the useful energy gain. They showed that in a steady state with a constant flow rate, the model gives better results.

Results of our computational tool were compared to the values collected from both the numerical and experimental results of Saleh [14] according to the operating parameters, specifically for the steady state tests. The flowchart of the code solves the mathematical model equations ((1)-(5)) of the solar collector for each operating configuration involved in the heat transfer process. Each component of the system is simulated using the same weather data as the experimental test. The parameters of the experimental system, as well as initial conditions, are entered as input in the simulation program. In the first step, the preprocessing provides a database with the physical properties of the water and air relevant to the problem, such as thermal conductivity, specific mass, and other parameters. The implementation also involves physical heat transfer and turbulence models. Therefore, the input data includes the total water flow, the solar radiation, and the ambient temperature. After the 
stabilisation of system temperatures, the simulation program provides a zero solar radiation flow over a period of time to simulate the cooling of the experimental model of reservoirs disconnected from solar collectors. Numerical results of Saleh [14] were found by using an adapted numerical model for a flat solar collector and performed by comparing the input and output temperatures with experimental results. Data collection was recorded every minute for inlet, outlet, and ambient temperatures. In the case of solar radiation, an average was recorded every 15 minutes. To verify the sensitivity of the mathematical model, when subjected to heating and then thereafter, the same input conditions were considered, such as dimensions and materials of the collector. Operating conditions were as follows: Solar Radiation: $800 \mathrm{~W} / \mathrm{m}^{2}$ constant for 1 hour; then zero radiation, ambient temperature is $20^{\circ} \mathrm{C}$, the collector inclination is $45^{\circ}$, the time interval is 120 minutes and the volumetric flow is taken $1.5 \mathrm{GPM}$.

In order to verify if results of the numerical model of the proposed model behaved according to results of the reference, the same collector was considered, that is, the flat type with glass cover, for water heating applications, with an external area of $2 \mathrm{~m}^{2}$. The collector is lined with aluminum frame and $5^{\prime \prime}$ thick rock wool insulation material at the bottom. Looking at Figure 1, we can see a comparison between the inlet and outlet temperature curves of numerical and experimental results obtained by Saleh [14] as well astemperature curves of numerical results obtained by the author. It is possible to verify a strong correlation between results.

3.2. Validation with Tested Model in the LPT Laboratory. The second step in the validation process is the comparison of our results with those obtained experimentally in our laboratory. The FPC under investigation was tested in the Research and Technology Centre of Energy (CRTEn), BorjCedria. It is, as displayed in Figure 2, detailed as follows: The collector has overall dimensions of $2.004 \times 1.004 \times 0.95 \mathrm{~m}^{3}$, a surface area of $2.12 \mathrm{~m}^{2}$ and the capacity of the absorber is 2.851 . The painting is highly selective with an absorption coefficient $95.3 \%$ and an emission factor $4.7 \%$. The solar collector was fixed so that the angle of incidence of the radiation is $45^{\circ}$. The solar collector test bench consists of the following:

(1) Heat pump to set the solar collector water inlet temperature.

(2) An anemometer to measure the wind speed.

(3) A flow meter for measuring the flow rate inside the sensor.

(4) A microcomputer for the acquisition of data as an Excel file.

During the test, the global solar radiation is measured by the calibrated first class pyranometer (Kipp \& Zonen) and the ambient temperature so that the probe was placed in a protected and ventilated cage placed at the height of $1.25 \mathrm{~m}$ from the surface of the trial. Finally, PT100 probes for

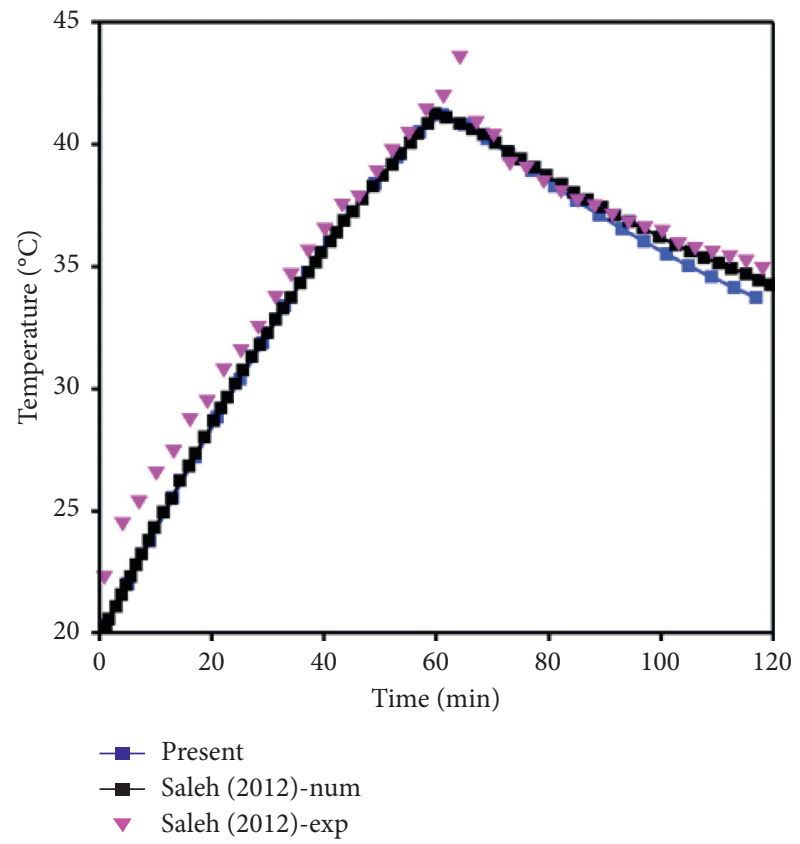

FIGURE 1: First step of the code validation: Comparison with results of Saleh [14].

measuring different temperatures (input, output, and ambient) were used. A multichannel digital data acquisition unit (type Agilent HP34970 A) was connected to the FPSC device to collect the data obtained during measurements. For the numerical investigation, ASHRAE data is used to obtain thermophysical properties of water.

In order to show the precision of the experimental investigation, we summarize in Table 1 measurement errors attributed to the uncertainly of measurements. In fact, uncertainties are mainly attributed to errors occurring during measurement and the errors of the measurement apparatus, the sensitiveness of the data acquisition system, and Pt100 temperature sensors.

Figure 3 is a representation of the instantaneous thermal efficiency curve of the solar collector $\eta_{\mathrm{en}}$ as a function of the reduced temperature $T_{\mathrm{r}}=\left(T_{\mathrm{m}}-T_{\mathrm{a}}\right) / G$ where $T_{\mathrm{m}}=\left(T_{\text {out }}+\right.$ $\left.T_{\text {in }}\right) / 2$ and $T_{\text {in }}$ is the inlet temperature. As it is predicted by a linear equation $\eta_{\mathrm{en}}=\eta_{0}-U_{\mathrm{L}} T_{\mathrm{r}}$, where $U_{\mathrm{L}}$ is the heat loss coefficient, $\eta_{\mathrm{en}}$ is almost linear, and slopes of curves are about -5.44 and -5.06 obtained numerically and experimentally, respectively. If we take into consideration the sensitivity of the equipment and the error occurring during the experimental investigation presented by error bars in Figure 2, we can affirm the accuracy of the proposed numerical model. Hence, the simulation program could reproduce with acceptable accuracy the real behavior of the FPC system.

Table 2 summarizes results of the measured ambient $T_{\mathrm{a}}$, the solar radiation $G$, the inlet temperature, and the rate of temperature increase $\Delta T=T_{\text {out }}-T_{\text {in }}$. The table also shows a comparison between computed values of energy and exergy efficiencies $\eta_{\mathrm{en}}$ and $\eta_{\mathrm{ex}}$ obtained numerically and experimentally. In general, results are encouraging and the 


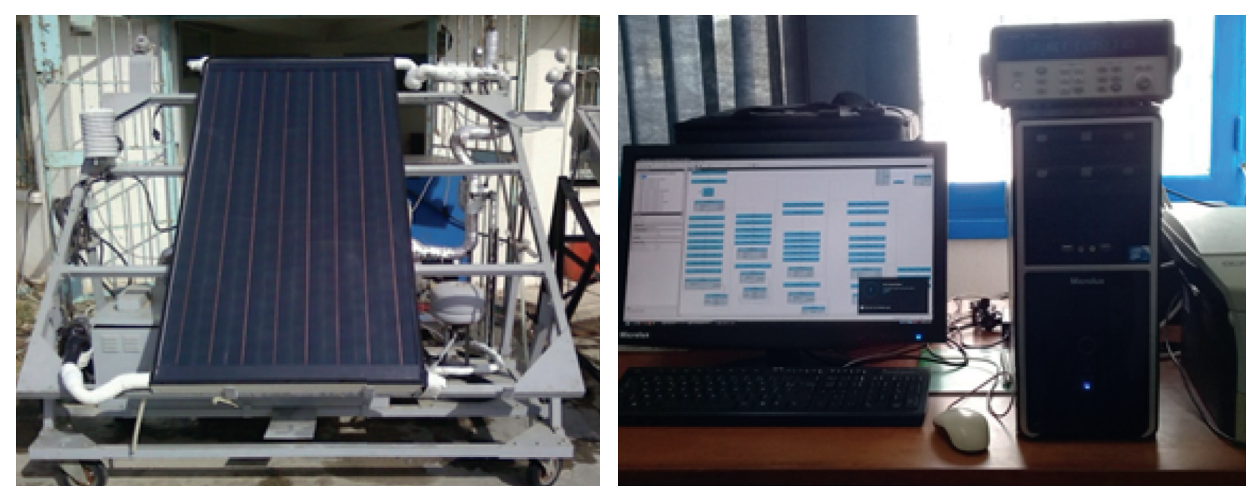

Figure 2: Experiment setup (tested FPSC and data acquisition toolbox).

TABle 1: Uncertainty of sensors at a typical test condition.

\begin{tabular}{lcc}
\hline Parameters & Units & Values \\
\hline Water temperature sensor & ${ }^{\circ} \mathrm{C}$ & \pm 0.05 \\
Ambient air temperature & ${ }^{\circ} \mathrm{C}$ & \pm 0.1 \\
Flow meter & $\mathrm{Kg} / \mathrm{s}$ & \pm 0.01 \\
Pyranometer & $\mathrm{W} / \mathrm{m}^{2}$ & \pm 50 \\
\hline
\end{tabular}

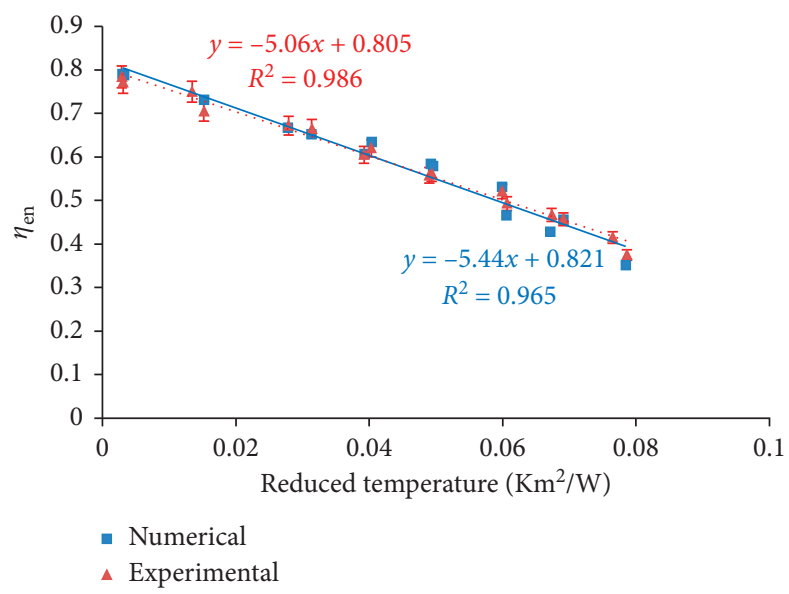

FIGURE 3: Present numerical and experimental results of the tested collector in CRTEn.

TAble 2: Performance test according to EN 12975 obtained numerically (thin line) and experimentally (bold line).

\begin{tabular}{|c|c|c|c|c|c|c|}
\hline Experimental time & $T_{\mathrm{a}}\left({ }^{\circ} \mathrm{C}\right)$ & $G\left(\mathrm{~W} / \mathrm{m}^{2}\right)$ & $T_{\text {in }}\left({ }^{\circ} \mathrm{C}\right)$ & $\Delta T\left({ }^{\circ} \mathrm{C}\right)$ & $\eta_{\mathrm{en}}(\%)$ & $\eta_{\mathrm{ex}}(\%)$ \\
\hline $10: 34: 34$ & 18.14 & 820.77 & 65.61 & $4.41-4.60$ & $46.61-49.3$ & $7.17-7.58$ \\
\hline $11: 18: 43$ & 19.51 & 874.17 & 75.99 & $4.32-4.75$ & $42.88-46.7$ & $7.56-8.24$ \\
\hline $11: 57: 53$ & 20.57 & 856.54 & 86.03 & $3.47-3.79$ & $35.21-37.5$ & $6.92-7.37$ \\
\hline $12: 44: 21$ & 18.24 & 874.90 & 17.09 & $7.93-7.73$ & $78.73-77.1$ & $0.83-0.75$ \\
\hline $12: 05: 12$ & 18.80 & 866.86 & 17.48 & $7.89-7.66$ & $79.02-78.4$ & $0.78-\mathbf{0 . 7 0}$ \\
\hline $12: 34: 54$ & 16.12 & 929.51 & 26.37 & $7.83-7.80$ & 73.09-70.5 & $3.63-3.46$ \\
\hline $13: 19: 33$ & 17.63 & 949.10 & 40.33 & $7.29-7.59$ & $66.72-67.2$ & $5.87-5.91$ \\
\hline $11: 39: 44$ & 17.38 & 890.23 & 50.02 & $6.51-6.46$ & $63.48-62.0$ & $7.38-7.18$ \\
\hline $12: 14: 52$ & 17.66 & 924.78 & 50.76 & $6.47-6.32$ & $60.72-60.5$ & $7.13-7.06$ \\
\hline $11: 35: 56$ & 19.02 & 910.34 & 60.73 & $6.13-5.79$ & $58.44-55.8$ & $8.21-7.79$ \\
\hline $12: 46: 42$ & 17.47 & 847.65 & 65.67 & $5.18-5.18$ & $53.10-52.1$ & $8.34-18.16$ \\
\hline $13: 19: 07$ & 16.07 & 852.37 & 39.59 & $6.40-6.46$ & $65.21-66.5$ & $5.84-5.93$ \\
\hline $13: 59: 14$ & 17.75 & 929.24 & 60.68 & $6.20-5.86$ & $57.97-56.2$ & $8.37-8.06$ \\
\hline $10: 57: 02$ & 17.35 & 877.09 & 75.61 & $4.61-4.70$ & 45.59-45.7 & $8.30-\mathbf{8 . 3 1}$ \\
\hline
\end{tabular}


proposed program was shown to be a reliable method for evaluating both energy and exergy performances of the FPC. The slight discrepancy between $\eta_{\mathrm{en}}$ and $\eta_{\mathrm{ex}}$ obtained by using the experimental set-up and simulation program can be explained by errors due to the misplacing of the temperature sensor or a faulty connection wire is suspected. Other reasons for the discrepancy are the used 1D mathematical model to compute the temperatures at each node and the simplified theoretical formula of the exergy efficiency, which does not take into account the pressure drops in the collector. The table shows that by increasing $\Delta T$, the energy efficiency decreases while the exergetic efficiency increases. When $\Delta T$ is high, the useful exergy rate decreases quickly.

\section{Results and Discussion}

Figure 4 shows the $\pm 50 \mathrm{~W} / \mathrm{m}^{2}$ of uncertainty in solar irradiation effects on the thermal efficiency of the tested collector. Note that $100 \mathrm{~W}$ is the standard uncertainty of the major calibrated first class pyranometer which is required by the EN 12975. As displayed in the figure, the uncertainty in the irradiance has an effect on both reduced temperature's results and thermal efficiency's values. More importantly, a more noticeable influence on the reduced temperature than on the efficiency of the collector is observed. More precisely, an uncertainty of $\pm 50 \mathrm{~W} / \mathrm{m}^{2}$ in $G$ affects the reduced temperature about $\pm 0.004 \mathrm{Km}^{2} / \mathrm{W}$. This uncertainty produces a deviation in efficiency results of about $5.5 \%$.

Figure 5 shows the effects of $\pm 1^{\circ} \mathrm{C}$ uncertainty in thermocouples measuring the ambient temperature on the thermal performance of the collector. It is clear from the figure that when the reduced temperature is small, i.e., the collector is at near-ambient temperature, the $2^{\circ} \mathrm{C}$ of uncertainty in the ambient temperature has no significant effect on the thermal efficiency. When the reduced temperature increases, the effect of the uncertainty appears on both $\mathrm{Tr}$ and $\eta_{e n}$. The figure also shows that when the collector is at far away-ambient temperature, uncertainty in the ambient temperature has an important effect on the result of the reduced temperature which decreases substantially. Since the reduced temperature gives rise to the difference between the mean collector and the ambient temperature, one can explain the accentuated effect of the ambient temperature on $T_{\mathrm{r}}$. The deviation reaches $0.033 \mathrm{Km}^{2} / \mathrm{W}$ and $9.9 \%$ in $T_{\mathrm{r}}$ and $\eta_{\text {en }}$, respectively. Therefore, the collector efficiency is significantly influenced by the ambient temperature. This trend of the results shows that both uncertainties measurements in the ambient temperature must be taken into account as for regression parameters [11].

Figure 6 shows the effect of $\pm 1^{\circ} \mathrm{C}$ of uncertainty when using Pt100 Thermometer at the inlet of the collector on its thermal performance. As shown in the figure, the $2^{\circ} \mathrm{C}$ of uncertainty in the inlet temperature has a slight effect on the result of the reduced temperature but has no effect on the thermal efficiency. In fact, this result is expected because the inlet temperature has no requirement in the test standard. More importantly, the uncertainty of $\pm 1^{\circ} \mathrm{C}$ in $T_{\text {in }}$ affects the reduced temperature by $\pm 0.001 \mathrm{Km}^{2} / \mathrm{W}$.

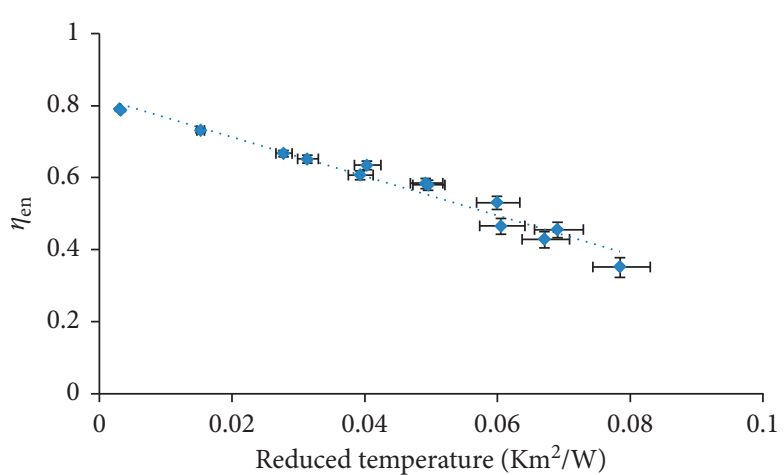

FIgURE 4: $\pm 50 \mathrm{~W} / \mathrm{m}^{2}$ uncertainty in irradiation effects on the thermal performance of the collector.

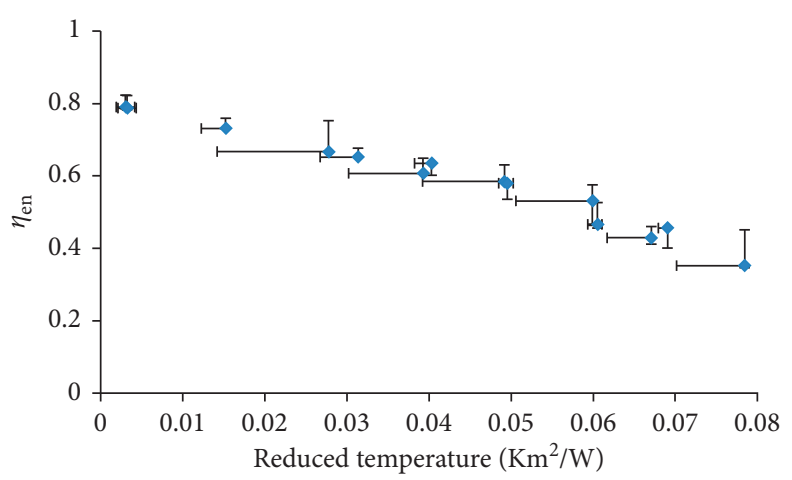

FIGURE 5: $\pm 1^{\circ} \mathrm{C}$ of deviation in ambient temperature effects on the thermal performance of the collector.

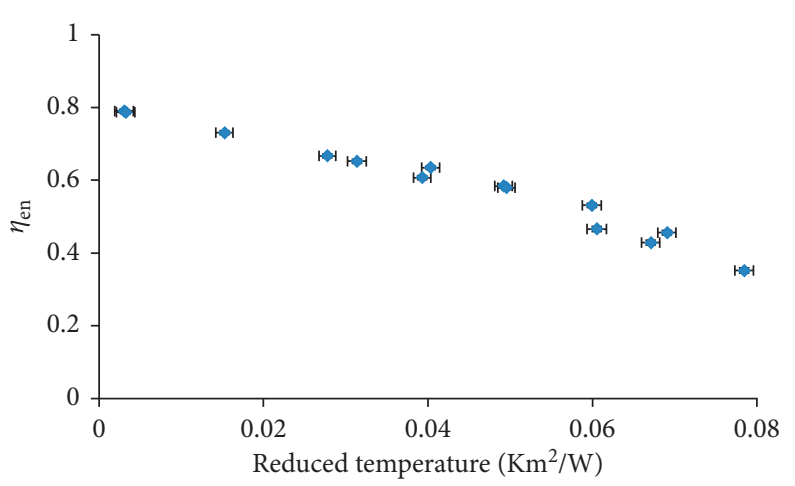

FIGURE 6: Effect of $\pm 1^{\circ} \mathrm{C}$ of uncertainty in temperature inlet effects on the thermal performance of the collector.

The flow rate uncertainty effect of $\pm 10 \%$ on thermal efficiency is shown in Figure 7. As displayed in the figure, the gap between measured and mean flow rate values has no effect on the $\eta_{\mathrm{en}}$ and it has a slight effect on the reduced temperature. When the deviation in mass flow rate is about $\pm 10 \%$, the uncertainty in $T_{\mathrm{r}}$ decreases about $0.002 \mathrm{Km}^{2} / \mathrm{W}$.

Figure 8 shows the effect of a deviation of about $\pm 10 \%$ in flow rate on the collector performance for a test sample. According to the figure, the uncertainty in the flow rate has a small effect on the temperatures of the absorber, the air gap, and the glass. Importantly, these deviations are about $0.9^{\circ} \mathrm{C}$, 


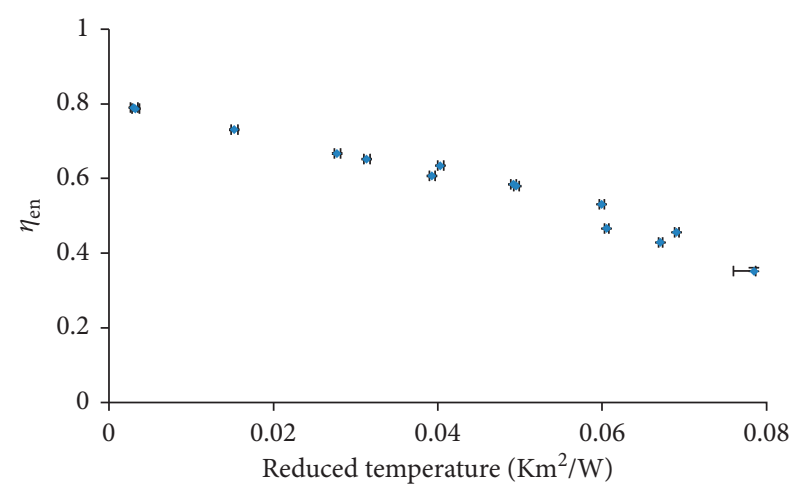

FIgURE 7: Effect of $\pm 10 \%$ flow rate uncertainty on the thermal efficiency.

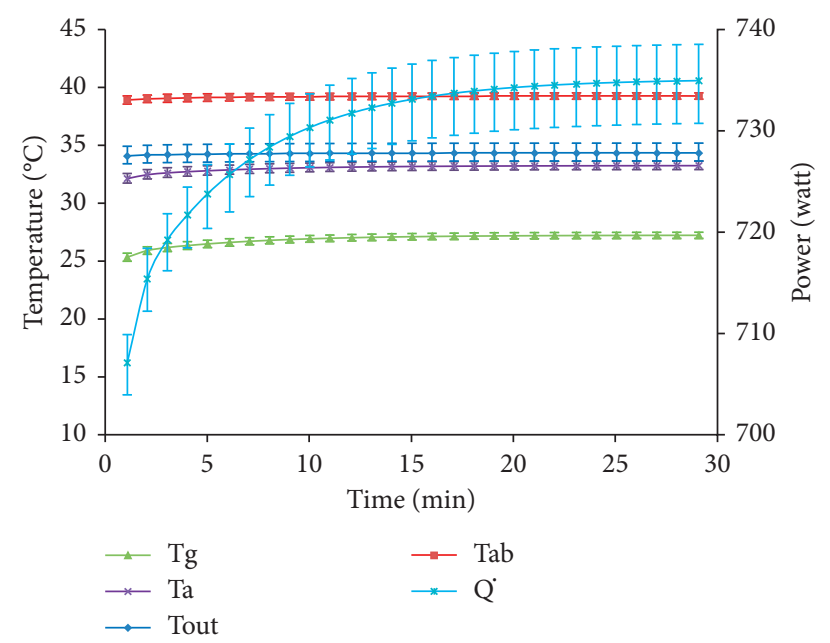

Figure 8: Effect of $\pm 10 \%$ deviation in the flow rate on the temperature histories for all the analyzed cross sections of the collector and its power output.

$0.8^{\circ} \mathrm{C}$, and $0.6^{\circ} \mathrm{C}$ for $T_{\mathrm{ab}}, T_{\mathrm{a}}$, and $T_{\mathrm{g}}$, respectively. A remarkable effect of uncertainty is observed in outlet temperature, which deviates by $1.5^{\circ} \mathrm{C}$. The effect is then accentuated in the power output of the collector which deviates by $6.8 \mathrm{~W}$.

It is important to note that apart from uncertainties in operating parameters, regression uncertainties should be taken into account and should not be neglected, as confirmed by Facão and Oliveira [7] and Sowmy et al. [8]. Table 3 reports the effect of measurement errors in several operating parameters on regression coefficients $\eta_{0}, a_{1}$ and $a_{2}$. The table reveals that the estimation in conversion factor mean value $\eta_{0}$ (efficiency for $T_{\mathrm{m}}=T_{\mathrm{am}}$ ) is affected by $1 \%$, $8.2 \%$, and $0.4 \%$ when there is an uncertainty in $G, T_{\mathrm{am}}$, and $T_{\text {in }}$. The heat loss coefficient $a_{1}$ is shifted by $\pm 84.79 \%$ when the uncertainty of measurement is about $\pm 1^{\circ} \mathrm{C}$. This trend of results means that other operating parameters do not have the same order of relevance as ambient temperature. With the same uncertainty, the heat loss coefficient dependent on temperature $a_{2}$ is moved by $0.022 \mathrm{Wm}^{-2} \mathrm{~K}^{-2}$. Mean uncertainties for linear analysis procedure were, respectively, $4.1 \%$
TABLE 3: Effects of uncertainties in input parameters on results of regression analysis.

\begin{tabular}{lcccc}
\hline Parameter & $\eta_{0}$ & $a_{1}\left(\mathrm{~W} / \mathrm{m}^{2} \mathrm{~K}\right)$ & $a_{2}\left(\mathrm{~W} / \mathrm{m}^{2} \mathrm{~K}^{2}\right)$ & $R^{2}$ \\
\hline Mean value & 0.792 & 3.064 & 0.034 & 0.980 \\
$G \pm 50 \mathrm{~W} / \mathrm{m}^{2}$ & $\pm 0.5 \%$ & $\pm 0.01 \%$ & $\pm 5.93 \%$ & $0.979-0.981$ \\
$\mathrm{~T}_{\mathrm{am}} \pm 1^{\circ} \mathrm{C}$ & $\pm 4.1 \%$ & $\pm 84.79 \%$ & $64.31 \%$ & $0.976-0.999$ \\
$\mathrm{~T}_{\mathrm{in}} \pm 1^{\circ} \mathrm{C}$ & $\pm 0.2 \%$ & $\pm 1.86 \%$ & $\pm 0.62 \%$ & 0.980 \\
\hline
\end{tabular}

and $2.6 \mathrm{Wm}^{-2} \mathrm{~K}^{-2}$ for $\eta_{0}$ and $a_{1}$. This trend of the results means that regression uncertainties do not have the same order of relevance as ambient temperature uncertainty.

Figure 9 reports the variation of the exergy efficiency versus the inlet temperature. The figure shows that the exergy efficiency increases with the inlet temperature. When the water is heated from $17.48^{\circ} \mathrm{C}$ to $26.37^{\circ} \mathrm{C}$, the exergy increases by $2.8 \%$. The highest exergy observed is equal to $8.3 \%$ for $T_{\text {in }}=75.61^{\circ} \mathrm{C}$. It is important to note that an optimum in exergy rate is observed by Ge et al. [23] and Farahat et al. [4].

Figure 10 shows the contribution of several operating parameters on the deviation in instantaneous energy efficiency values. The effect of uncertainty in $\dot{m}$ and $T_{\text {in }}$ is around $1.09 \%$ and $1.42 \%$, respectively. However, the ambient temperature was found to be the most influencing parameter, and its effect reaches $13.7 \%$. The second important parameter is the solar irradiance, and its value may affect the energy efficiency by $5.47 \%$.

Figure 11 shows the contribution of several operating parameters on the deviation in exergy efficiency. The effect of uncertainty in $\dot{m}$ and $T_{\text {in }}$ is around $0.34 \%$ and $0.53 \%$, respectively. However, the ambient temperature was found to be the most influencing parameter and its effect reaches $3.89 \%$. The second important parameter is the solar irradiance and its value may affect the exergy efficiency by $1.11 \%$.

The aim of this section is the analysis of the effect of a deviation in thermophysical properties of the working fluid on energetic and exergetic efficiencies of the collector. Therefore, we consider a new class of heat transfer fluids composed of metal nanometer-sized conductive particles dispersed in the base fluid often called nanofluid. The majority of published works highlight that classical correlations are not able to predict the superior characteristics of convective heat transfer of nanofluids. Figure 12 shows the efficiency of the collector with ethylene-glycol mixture (E-G) $(30: 70)$ with and without MCNT nanoparticles at $0.15 \mathrm{v} \%$ versus the reduced temperature parameters. Experimental conditions are kept the same as the previous section and thermophysical properties data of E-G + MCNT nanofluid are given by Kumaresan and Velraj [24]. These properties depend on both the volume fraction and the temperature. The figure clearly shows that the efficiency of the collector using E-G + MCNT nanofluid is highest and the $\eta_{0}$ values when using pure E-G are the lowest. This result agrees well with previous investigations found in the literature $[25,26]$. The $\eta_{0}$ values for E-G with and without MCNT nanoparticles are $84.7 \%$ and $75.4 \%$, respectively. Therefore adding nanoparticles enhances energy parameter $\eta_{0}$ value by about $9.3 \%$. 


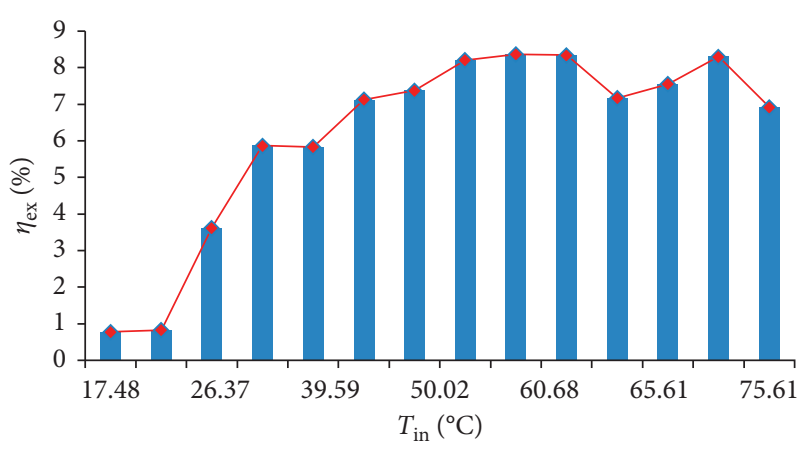

Figure 9: Variation of the exergy efficiency versus the inlet temperature.

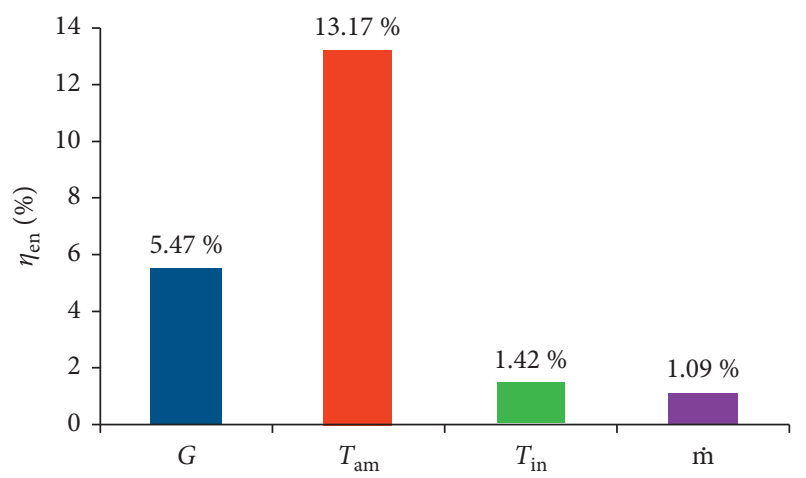

FIgURE 10: Change in energy efficiency per $10 \%$ in parameter values for a mean value.

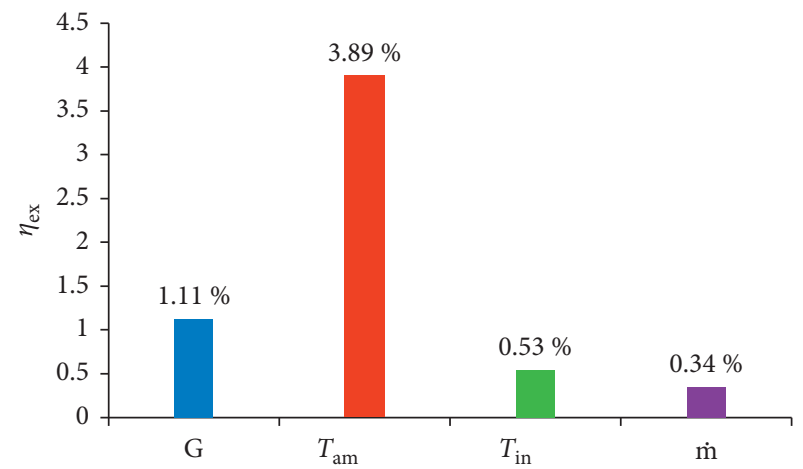

Figure 11: Change in exergy efficiency per $10 \%$ in operating parameter values for a mean value.

In order to reveal the effect and the importance of the determination of thermophysical properties of the working fluid on the thermal performance of the collector, numerical investigations were carried out as follows:

(1) Investigation I: The working fluid is the EthyleneGlycol.

(2) Investigation II: The working fluid is at $0.15 \mathrm{v} \%$ Carbon Nanotubes + Ethylene-Glycol (30:70). Thermophysical properties are extracted from data of Kumaresan and Velraj [24]. Other investigations are performed using the same nanofluid as follows:

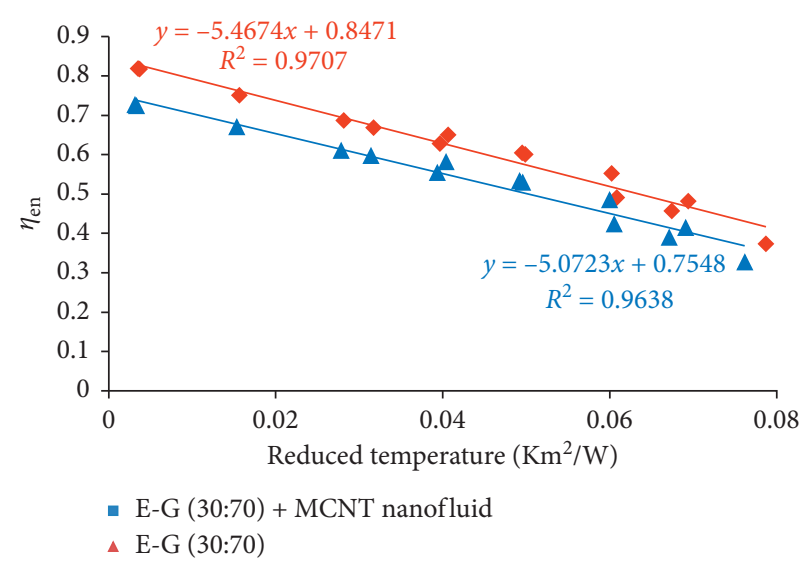

Figure 12: Efficiency of the collector with ethylene-glycol mixture $(30: 70)$ with and without CNT nanoparticles at $0.15 \mathrm{v} \%$.

(i) Investigation II-a: Only $\lambda_{\mathrm{f}}$ is computed by using Maxwell's model as follows [27]:

$$
\lambda_{\mathrm{f}}=\lambda_{\mathrm{bf}} \frac{\left(\lambda_{\mathrm{s}}+2 \lambda_{\mathrm{EG}}\right)-2 \varphi\left(\lambda_{\mathrm{EG}}-\lambda_{\mathrm{s}}\right)}{\left(\lambda_{\mathrm{s}}+2 \lambda_{\mathrm{EG}}\right)+\varphi\left(\lambda_{\mathrm{EG}}-\lambda_{\mathrm{s}}\right)}
$$

where $\varphi=0.15 \%$ is volume fraction, $\lambda_{\mathrm{s}}$ and $\lambda_{\mathrm{EG}}$ are the thermal conductivities of the MWCNT nanoparticles and the E-G fluid, respectively.

(ii) Investigation II-b: Only $\mu_{\mathrm{f}}$ is computed by using Brinkman's model [28] by using the following equation:

$$
\mu_{\mathrm{f}}=(1-\varphi)^{-2.5} \mu_{\mathrm{EG}}
$$

where $\mu_{\mathrm{EG}}$ is the E-G dynamic viscosity.

(iii) Investigation II-c: $C_{\mathrm{f}}$ is computed by using Xuan and Roetzel's model which is claimed to be the fittest for getting specific heat of nanofluid [29,30]:

$$
\left(\rho C_{\mathrm{p}}\right)_{\mathrm{f}}=(1-\varphi)\left(\rho C_{\mathrm{p}}\right)_{\mathrm{EG}}+\varphi\left(\rho C_{\mathrm{p}}\right)_{\mathrm{s}}
$$

(iv) Investigation II-d: $\mu_{\mathrm{f}}, \lambda_{\mathrm{f}}$, and $C_{\mathrm{p}}$ are computed from prescribed theoretical correlations and combined together.

Figure 13 presents the effect of correlation determining the viscosity $\mu_{\mathrm{f}}$, the thermal conductivity $\lambda_{\mathrm{f}}$, and the specific heat $C_{p}$ of nanofluid on the thermal efficiency of the collector. Correlations used are Maxwell's model, Brinkman's model, and Xuan and Roetzel's model for $\mu_{\mathrm{f}}, \lambda_{\mathrm{f}}$, and $C_{\mathrm{p}}$, respectively. Reference characteristic parameters of the flat plate solar collector use thermophysical properties of E-G + MCNT nanofluid published by Kumaresan and Velraj [24]. The figure indicates that when we use Brinkman's model for the viscosity, $\eta_{0}$ increases about $6.3 \%$. By using Maxwell's model for the thermal conductivity, $\eta_{0}$ increases about $1.4 \%$ and the specific heat formulae of the nanofluid 


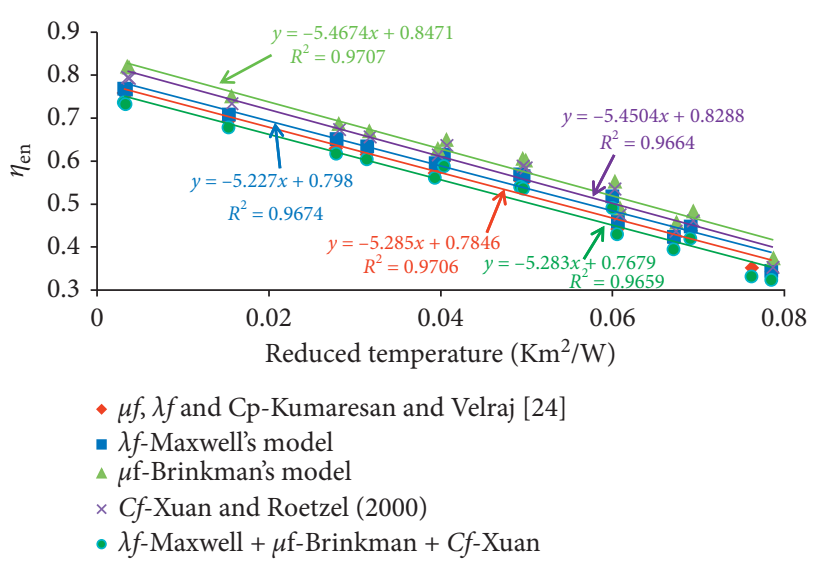

FIgURE 13: Effect of correlation determining thermophysical properties of nanofluid on the thermal efficiency of the collector.

deviate the thermal efficiency result by about $4.4 \%$. This trend of results reveals the importance of the determination of thermophysical properties of the nanofluid (and hence the preparation step of the nanofluid) for the accuracy of fitting parameters.

As expected, the specific heat decreased when using the correlation prescribed while thermal conductivity and viscosity increased. The increase in viscosity is due to the fact that nanoparticles are at low concentrations $(0.15 \%)$. The increase in viscosity has exceeded the improvement of the thermal conductivity which is manifested in the figure by the remarkable effect of viscosity compared to other thermophysical parameters effects. This also explains some inconsistencies among experimental evaluations of the thermal performance of nanofluids in thermal systems [31, 32]. Especially when the uncertainty in the heat specific capacity of the nanofluid increases hugely, the nanofluid improves the outlet temperature without increasing the efficiency.

Figure 14 shows the variation of the exergy efficiency versus the inlet temperature with E-G and E-G + MCNT nanofluid at $0.15 \mathrm{v} \%$ using thermophysical properties found by Kumaresan and Velraj [24] and by using Maxwell's model, Brinkman's model, and Xuan and Roetzel's correlation. By using prescribed theoretical correlations, the exergy efficiency takes values close to those of the collector in the absence of nanoparticles. By using values obtained experimentally by Kumaresan and Velraj [24], the exergy increases substantially. The maximum enhancement in exergy efficiency is obtained for $T_{\text {in }}=75.76^{\circ} \mathrm{C}$ and is equal to $1.18 \%$. This result reflects the fact that theoretical correlations of thermophysical properties have a great influence on heat transfer characteristics and hence on the energy and exergy efficiency of the collector.

\section{Conclusions}

In this work, a 1D mathematical model was developed and implemented in order to assess the sensitivity of energy and exergy performances of a Flat Plate Solar Collector (FPSC) according to EN 12975 procedure. The proposed method allows quantifying effects of uncertainties of both operating

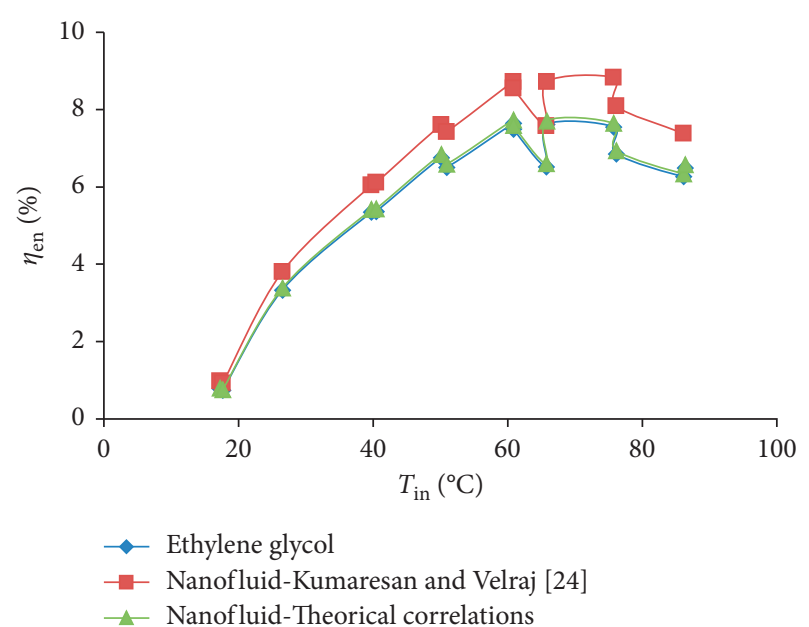

FIGURE 14: Variation of the exergy efficiency of the collector versus the inlet temperature with E-G and E-G + MCNT at $0.15 \mathrm{v} \%$ using thermophysical properties obtained by Kumaresan and Velraj [24] and by using empirical correlations.

conditions and thermophysical properties of working fluid on the performance estimation of the collector. The main results of numerical and experimental analysis gave the following conclusions:

(1) Results of the computational program are in good agreement with experimental measurements and benchmark solutions available in literature in terms of collector efficiency curve and outlet temperature, respectively. The proposed program was shown to be a reliable method for understanding major measurement parameter sensitivities in efficiencies and their uncertainties.

(2) During the test procedure, the ambient temperature is found to be the most influencing parameter on the performance estimation and a deviation about $\pm 1^{\circ} \mathrm{C}$ may affect the energy efficiency by $13.7 \%$ and the exergy efficiency by $3.9 \%$.

(3) When $0.15 \mathrm{v} \%$ MWCNT-E-G (30:70) nanofluid is used as working fluid, uncertainties in its thermophysical properties lead to important deviations in both energy and exergy efficiencies, and results show that common correlations are not able to predict the collector's performance neither in terms of energy nor in exergy. Especially, the deviation in exergy efficiency reaches $1.18 \%$.

\section{Nomenclature}

$C: \quad$ Specific heat $(\mathrm{J} /(\mathrm{kg} \cdot \mathrm{K}))$

$\rho: \quad$ Density $\left(\mathrm{kg} / \mathrm{m}^{3}\right)$

$V: \quad$ Volume $\left(\mathrm{m}^{3}\right)$

T: $\quad$ Temperature (K)

$h$ : Heat transfer coefficient $\left(\mathrm{W} /\left(\mathrm{m}^{2} \cdot \mathrm{K}\right)\right)$

$\alpha$ : Absorption coefficient

$G$ : Heat flux of solar radiation $\left(\mathrm{W} / \mathrm{m}^{2}\right)$

$p: \quad$ Tube pitch $(\mathrm{m})$

$\Delta z: \quad$ Spatial size of control volume (m) 


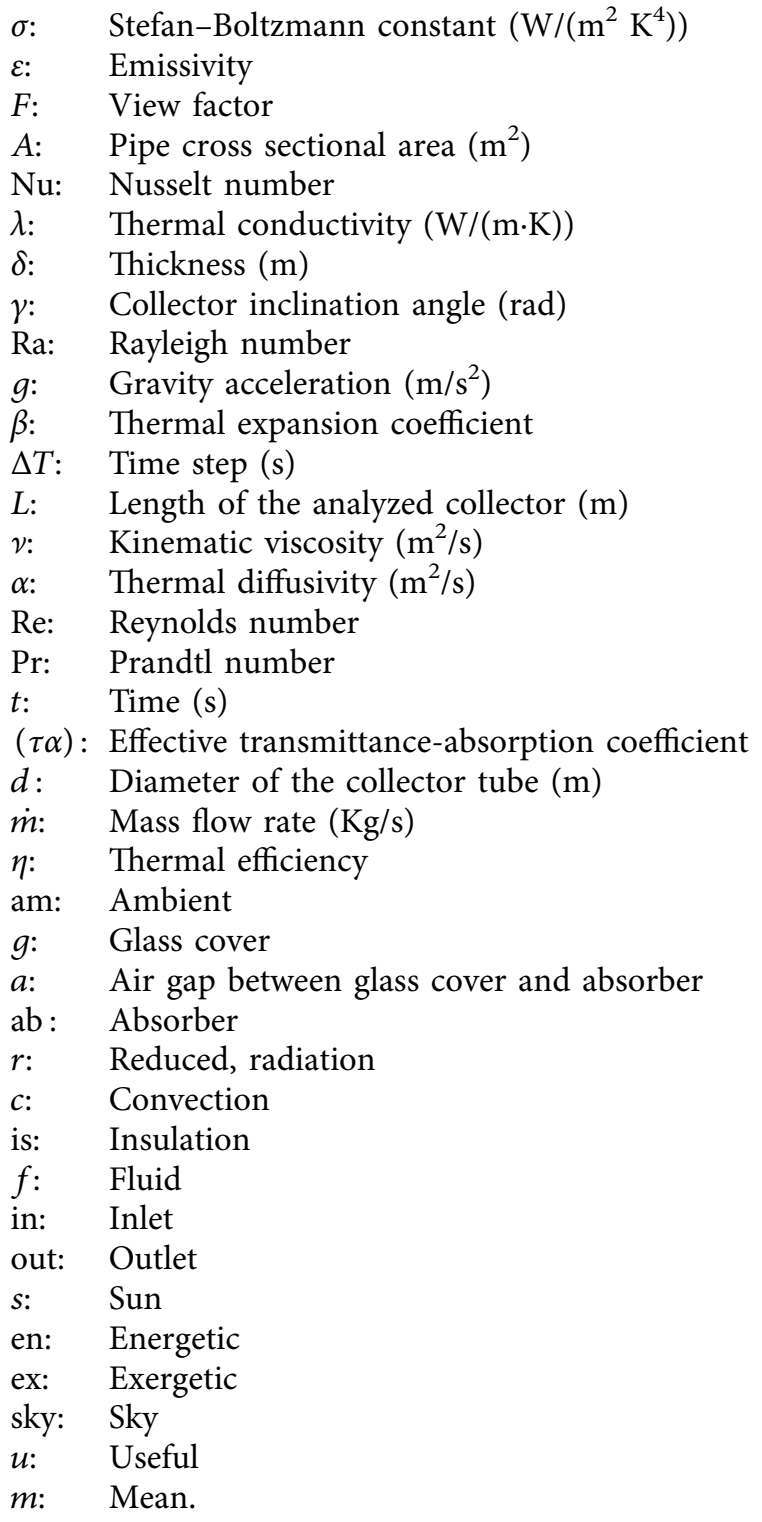

\section{Data Availability}

The data used to support the findings of this study are included within the article.

\section{Disclosure}

The research was performed as part of the $\mathrm{PhD}$ thesis of Intissar Harrabi and the employment of Mohamed Hamdi in the Research and Technology Centre of Energy of BorjCedria, Tunisia.

\section{Conflicts of Interest}

The authors declare that there are no conflicts of interest with respect to the research, authorship, and/or publication of this article.

\section{References}

[1] M. B. A. Sghari and S. Hammami, "Energy, pollution, and economic development in Tunisia," Energy Reports, vol. 2, pp. 35-39, 2016.

[2] A. Ege and H. M. Şahin, "Determination of uncertainties in energy and exergy analysis of a power plant," Energy Conversion and Management, vol. 85, pp. 399-406, 2014.

[3] S. A. Kalogirou, S. Karellas, K. Braimakis, C. Stanciu, and V. Badescu, "Exergy analysis of solar thermal collectors and processes," Progress in Energy and Combustion Science, vol. 56, pp. 106-137, 2016.

[4] S. Farahat, F. Sarhaddi, and H. Ajam, "Exergetic optimization of flat plate solar collectors," Renewable Energy, vol. 34, no. 4, pp. 1169-1174, 2009.

[5] R. Tang, Z. Li, H. Zhong, and Q. Lan, "Assessment of uncertainty in mean heat loss coefficient of all glass evacuated solar collector tube testing," Energy Conversion and Management, vol. 47, no. 1, pp. 60-67, 2006.

[6] R. Kicsiny, "Multiple linear regression based model for solar collectors," Solar Energy, vol. 110, pp. 496-506, 2014.

[7] J. Facão and A. C. Oliveira, "Experimental uncertainty analysis in solar collectors," International Journal of Ambient Energy, vol. 27, no. 2, pp. 59-64, 2006.

[8] D. S. Sowmy, P. J. Schiavon Ara, and R. T. A. Prado, "Uncertainties associated with solar collector efficiency test using an artificial solar simulator," Renewable Energy, vol. 108, pp. 644-651, 2017.

[9] E. Mathioulakis, K. Voropoulos, and V. Belessiotis, "Assessment of uncertainty in solar collector modeling and testing," Solar Energy, vol. 66, no. 5, pp. 337-347, 1999.

[10] V. Sabatelli, D. Marano, G. Braccio, and V. K. Sharma, "Efficiency test of solar collectors: uncertainty in the estimation of regression parameters and sensitivity analysis," Energy Conversion and Management, vol. 43, no. 17, pp. 2287-2295, 2002.

[11] N. Rehman, M. Uzair, M. A. Siddiqui, and M. Khamooshi, "Regression models and sensitivity analysis for the thermal performance of solar flat-plate collectors," Arabian Journal for Science and Engineering, vol. 44, no. 2, pp. 1119-1127, 2019.

[12] R. Karwa and S. Baghel, "Effect of parametric uncertainties, variations, and tolerances on thermohydraulic performance of flat plate solar air heater," Journal of Solar Energy, vol. 2014, pp. 1-18, 2014.

[13] W. Zima and P. Dziewa, "Modelling of liquid flat-plate solar collector operation in transient states," Proceedings of the Institution of Mechanical Engineers, Part A: Journal of Power and Energy, vol. 225, no. 1, pp. 53-62, 2011.

[14] A. M. Saleh, "Modeling of flat-plate solar collector operation in transient states," Master Thesis in Science Engineering, Purdue University Fort Wayne, Fort Wayne, IN, USA, 2012.

[15] A. Saleh, DW. Mueller, and H. I. Abu-Mulaweh, "Flat-Plate solar collector in transient operation: modeling and measurements," Journal of Thermal Science and Engineering Applications, vol. 7, no. 1, pp. 15-21, 2013.

[16] J. Cadafalch, "A detailed numerical model for flat-plate solar thermal devices," Solar Energy, vol. 83, no. 12, pp. 2157-2164, 2009.

[17] K. G. T. Hollands, T. E. Unny, G. D. Raithby, and L. Konicek, "Free convective heat transfer across inclined air layers," Journal of Heat Transfer, vol. 98, no. 2, pp. 189-193, 1976.

[18] J. A. Duffie and W. A. Beckman, Solar Engineering of Thermal Processes, John Wiley \& Sons, New York, NY, USA, 3rd edition, 2006. 
[19] L. Adelard, F. Pignolet-Tardan, T. Mara, P. Lauret, F. Garde, and H. Boyer, "Sky temperature modelisation and applications in building simulation," Renewable Energy, vol. 15, no. 14, pp. 418-430, 1998.

[20] H. S. Heaton, W. C. Reynolds, and W. M. Kays, "Heat transfer in annular passages. Simultaneous development of velocity and temperature fields in laminar flow," International Journal of Heat and Mass Transfer, vol. 7, no. 7, pp. 763-781, 1964.

[21] S. M. Jeter, "Maximum conversion efficiency for the utilization of direct solar radiation," Solar Energy, vol. 26, no. 3, pp. 231-236, 1981.

[22] F. Hilmer, K. Vajen, A. Ratka, H. Ackermann, W. Fuhs, and O. Melsheimer, "Numerical solution and validation of a dynamic model of solar collectors working with varying fluid flow rate," Solar Energy, vol. 65, no. 5, pp. 305-321, 1999.

[23] Z. Ge, H. Wang, H. Wang, S. Zhang, and X. Guan, "Exergy analysis of flat plate solar collectors," Entropy, vol. 16, no. 5, pp. 2549-2567, 2014.

[24] V. Kumaresan and R. Velraj, "Experimental investigation of the thermo-physical properties of water-ethylene glycol mixture based CNT nanofluids," Thermochimica Acta, vol. 545, pp. 180-186, 2012.

[25] S. K. Verma, A. K. Tiwari, and D. S. Chauhan, "Experimental evaluation of flat plate solar collector using nanofluids," Energy Conversion and Management, vol. 134, pp. 103-115, 2017.

[26] M. Eltaweel and A. A. Abdel-Rehim, "Energy and exergy analysis of a thermosiphon and forced-circulation flat-plate solar collector using MWCNT/Water nanofluid," Case Studies in Thermal Engineering, vol. 14, Article ID 100416, 2019.

[27] J. C. Maxwell-Garnett, "Colours in metal glasses and in metallic films," Philosophical Transactions of the Royal Society A, vol. 203, pp. 385-420, 1904.

[28] H. C. Brinkman, "The viscosity of concentrated suspensions and solutions," The Journal of Chemical Physics, vol. 20, no. 4, p. 571, 1952.

[29] Y. Xuan and W. Roetzel, "Conceptions for heat transfer correlation of nanofluids," International Journal of Heat and Mass Transfer, vol. 43, no. 19, pp. 3701-3707, 2000.

[30] I. M. Shahrul, I. M. Mahbubul, S. S. Khaleduzzaman, R. Saidur, and M. F. M. Sabri, "A comparative review on the specific heat of nanofluids for energy perspective," Renewable and Sustainable Energy Reviews, vol. 38, pp. 88-98, 2014.

[31] R. Mondragón, D. Sánchez, R. Cabello, R. Llopis, and J. E. Juliá, "Flat plate solar collector performance using alumina nanofluids: experimental characterization and efficiency tests," PLoS One, vol. 14, no. 2, pp. 1-18, 2019.

[32] N. Purohit, S. Jakhar, P. Gullo, and M. S. Dasgupta, "Heat transfer and entropy generation analysis of alumina/water nanofluid in a flat plate $\mathrm{PV} / \mathrm{T}$ collector under equal pumping power comparison criterion," Renewable Energy, vol. 120, pp. 14-22, 2018. 